\title{
Review
}

\section{Morphological foundations of pain processing in dental pulp}

\author{
Yong-Chul Bae ${ }^{1)}$ and Atsushi Yoshida ${ }^{2}$ \\ 1) Department of Anatomy and Neurobiology, School of Dentistry, Kyungpook National University, Daegu, Republic of Korea \\ ${ }^{2}$ Department of Oral Anatomy and Neurobiology, Graduate School of Dentistry, Osaka University, Suita, Japan
}

\begin{abstract}
Dental pulp is densely innervated by sensory afferents that are primarily involved in nociception. Elucidating the type and properties of these afferents and their distribution patterns within the dental pulp is crucial for understanding the mechanisms of acute dental pain and dental hypersensitivity. Recent studies on the release of the transmitter glutamate and the expression of glutamate receptors and vesicular glutamate transporters (VGLUT) in the pulpal axons and trigeminal ganglion (TG) have suggested the possibility of a distinct glutamate signaling mechanism underlying the peripheral processing of dental pain. This review discusses recent findings on the innervation of dental pulp and glutamate signaling by pulpal axons. First, recent findings on the morphological features and types of axons innervating the dental pulp are summarized. Then, glutamate signaling in the dental pulp and changes in the expression of VGLUT1 and VGLUT2 in the pulpal axons and TG neurons following pulpal inflammation are explained. Finally, findings on glutamate release from odontoblasts are briefly described.
\end{abstract}

Keywords; dental pulp, glutamate signaling, pulpal axons, vesicular glutamate transporter

\section{Introduction}

Dental pulp is a useful organ for studying the peripheral mechanisms of pain. Activation of the pulpal nerve by many types of stimuli, including chemical, mechanical, and thermal stimuli, primarily induces painful sensations even though it is innervated by various types of sensory nerve fibers, including $A \beta$ large myelinated fibers [1-3]. Elucidation of the types and properties of nerve fibers innervating dental pulp and of the sensory receptors and ion channels expressed in each type of pulpal nerve fiber is crucial for understanding the peripheral mechanisms of dental pain. Recently, many studies have reported expressions of glutamate receptors and various molecules involved in the release of glutamate in pulpal axons $[4,5]$ and their upregulation in inflamed pulp [6,7]. This suggests that glutamate signaling, associated with the pulpal nerve may play a crucial role in acute and pathologic dental pain.

This review summarizes recent findings on the innervation of dental pulp and glutamate signaling associated with intrapulpal axons, which may assist understanding of peripheral mechanisms of dental pain.

\section{Types and morphological features of axons innervating dental pulp} Types of axons innervating dental pulp

Dental pulp contains a unique sensory system that primarily produces painful sensations by various external stimuli [1]. Many electron microscopic (EM) studies have revealed that $70-90 \%$ of the axons within the dental pulp are unmyelinated "C" fibers and the remaining small proportion comprises small myelinated "A" fibers $[1,8]$. Many studies have also shown that intrapulpal axons arise from larger extrapulpal (parent) axons; thus, Thus, the axons innervating the dental pulp: 1) have higher conduction velocity in their extrapulpal segments than in their intrapulpal segments

Correspondence to Dr. Yong Chul Bae, Department of Anatomy and Neurobiology, School of Dentistry, Kyungpook National University, 188-1, 2-Ga, Samdeok-Dong, Jung-Gu, Daegu 41940, Republic of Korea

Fax: +82-53-426-7731 E-mail: ycbae@knu.ac.kr

doi.org/10.2334/josnusd.19-0451

DN/JST.JSTAGE/josnusd/19-045
$[9,10]$; 2) have a higher ratio of myelinated to unmyelinated axons in the extrapulpal segment (e.g. inferior alveolar nerve) than in the intrapulpal segment $[11,12]$. And 3) although most intrapulpal axons are unmyelinated, most sensory neurons innervating the dental pulp in the trigeminal ganglion (TG) are large- and medium-sized which are usually associated with large myelinated "A $\beta$ " fibers and small myelinated "A $\delta$ " fibers, respectively $[11,13]$.

An EM study employing retrograde tracing indicated that the parent axons innervating the rat molar pulp at the sensory root of the TG consist of 1) mostly (76\%) small myelinated A $\delta$ fibers, which are associated with the transduction of sharp, well-localized pain, and 2) many fewer unmyelinated fibers (4\%), which are associated with the transduction of diffuse, dull pain, and 3 ) a significant fraction (20\%) of large myelinated $\mathrm{A} \beta$ fibers, which are associated with the transduction of mechanical, non-noxious stimuli (Fig. 1) [2]. Some of the large myelinated $A \beta$ fibers innervating dental pulp may evoke pain by low-threshold stimuli and contribute to dentin sensitivity [14] and/or may be nociceptive fibers that respond to noxious stimuli [15]. This assumption is supported by the findings that about $20 \%$ of the large myelinated $A \beta$ fibers are nociceptive [15] and that some large myelinated $A \beta$ fibers project to the superficial lamina of the spinal dorsal horn where spinal nociceptive neurons are concentrated [16].

\section{Morphological features of axons within the dental pulp}

The myelinated axons of the primary sensory neurons usually lose their myelin sheath during their course from neuronal cell bodies to peripheral targets (Fig. 2) [17,18], which exposes several receptors and ion channels on the membrane of the unmyelinated part of the axon: these receptors and ion channels can be activated by various stimuli and extracellular ligands.

Previous EM studies identified both myelinated and unmyelinated axons in dental pulp $[19,20]$, but the authors did not elucidate where and how the morphology of the parent myelinated axons change between their origin in the TG and their target in the dental pulp, or within the dental pulp itself. It was shown that virtually all axons in the sensory roots of the TG that are immunopositive for parvalbumin $(\mathrm{PV}+)$ are myelinated [21]. A study using PV as a marker for myelinated axons indicated that the parent myelinated axons innervating human dental pulp undergo significant morphological changes during their peripheral course before and after they enter the dental pulp [3]. Thus, about $66 \%, 79 \%$, and $99 \%$ of the PV+ axons in the radicular pulp, the core of the coronal pulp, and the peripheral pulp, respectively, were unmyelinated (Fig. 3), implying that $66 \%$ of the parent axons that are myelinated at the TG lose their myelin before reaching the dental pulp. Also, $40 \%$ of the myelinated axons at the apical foramen become unmyelinated before reaching the core of the coronal pulp, and the remaining $60 \%$ become unmyelinated in their course from the core of the coronal pulp to the peripheral pulp. This suggests that most unmyelinated fibers in the peripheral pulp come from myelinated parent axons.

Expression and distribution of receptors and ion channels in the axons of dental pulp

Many receptors and channels are expressed in the pulpal axons and TG neurons that innervate dental pulp. They are activated by a variety of stimuli and are involved in the generation and signal transduction of acute nociceptive and pathological pain. The number that have been discovered have rapidly increased over the last decade and those that have been studied most extensively are: 1) thermosensitive channels, including the heatsensing channels transient receptor potential vanilloid (TRPV) $1\left(>43^{\circ} \mathrm{C}\right)$, TRPV2 $\left(-52^{\circ} \mathrm{C}\right)$, TRPV4 $\left(27-35^{\circ} \mathrm{C}\right)$, and transient receptor potential melas- 


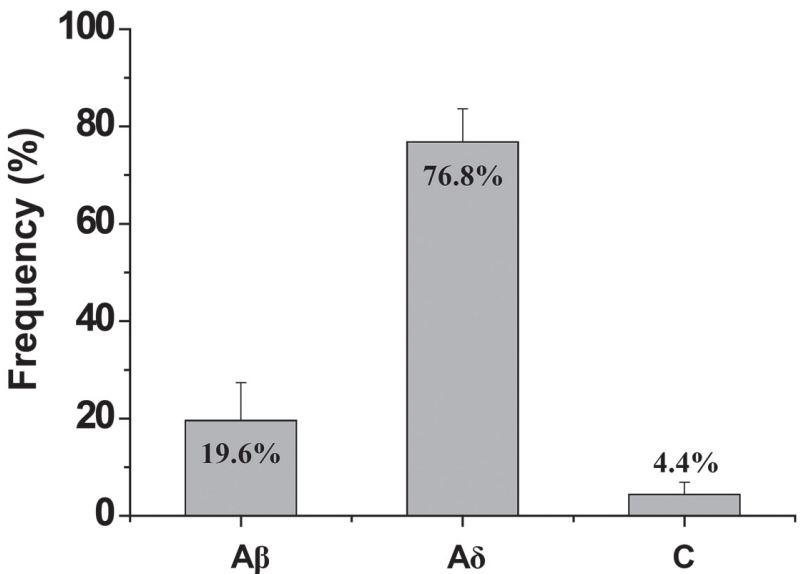

Fig. 1 Frequency (mean \pm S.D., \%) of the three types of parent axons innervating the rat molar pulp at the proximal sensory root of the trigeminal ganglion. Data are modified from the study by Paik et al. [2].

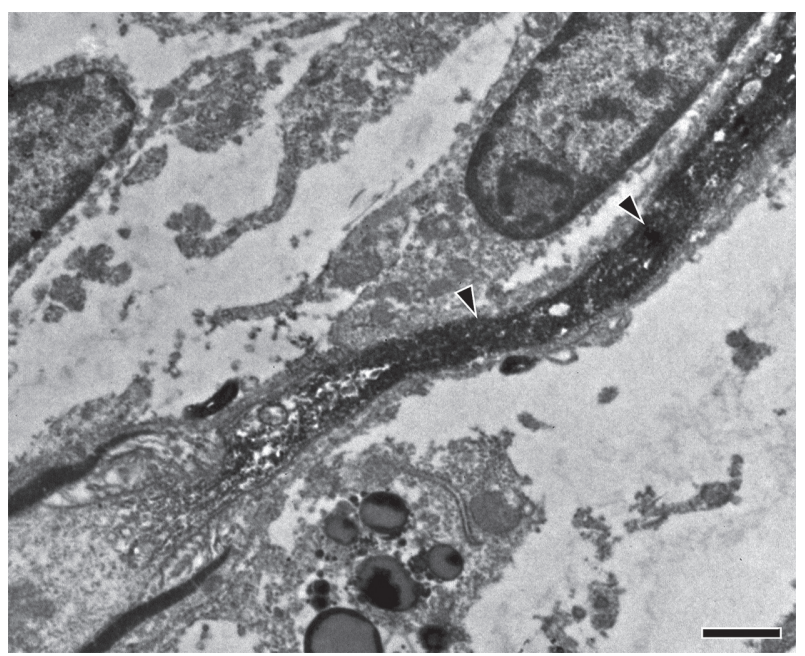

Fig. 2 Electron micrograph showing the morphological change of a myelinated axon within the rat molar pulp immunostained for NF200. A myelinated axon loses its myelin sheath and becomes unmyelinated. Arrowheads indicate the electron-dense immunostaining for NF200 in the unmyelinated segment of the axon. Scale bar $=1 \mu \mathrm{m}$

tatin (TRPM) $3\left(>40^{\circ} \mathrm{C}\right)$ and the cold-sensing channels TRPM8 $\left(<26^{\circ} \mathrm{C}\right)$ and transient receptor potential ankyrin 1 (TRPA1) $\left.\left(<17^{\circ} \mathrm{C}\right) ; 2\right)$ mechanosensitive channels, including TRPV1, TRPV2, TRPV4, TRPM3, TRPA1, epithelial sodium channel (ENaC), acid-sensing ion channel 3(ASIC3), and Piezo-type mechanosensitive ion channel component 2 (PIEZO2); 3) other channels, including the ATP-binding purinergic receptors P2X2 and $\mathrm{P} 2 \mathrm{X} 3$, and the hyperpolarization-activated cyclic nucleotide-gated channels $\mathrm{HCN}[5]$.

Recent immunohistochemical studies showed the distribution of coldsensing channels TRPA1 and TRPM8 in the axons of dental pulp [7,22]: thus, nerve fibers expressing TRPA1 and/or TRPM8 are scant in the radicular pulp and the core of the coronal pulp, but they branch extensively and form a network of fibers in the peripheral pulp: many TRPM8-positive axons were also found to penetrate the dentinal tubules toward the enamel. The latter observation, in particular, may have clinical implications since it indicates that the TRPA1- and TRPM8-mediated pain from noxious cold is primarily perceived at the level of the peripheral pulp and dentin. This suggests that applying TRPA1 or TRPM8 blockers to the peripheral pulp and dentinal tubules may be more effective in relieving dentin cold hypersensitivity and there may be fewer side effects than applying those blockers systemically.

The HCN contributes to hyperpolarization-induced membrane currents and is implicated in pathological pain following nerve injury and inflammation, but not in acute nociceptive pain [23-25]. Two major isoforms of $\mathrm{HCN}, \mathrm{HCN} 1$ and $\mathrm{HCN} 2$, are expressed in pulpal axons. They are primarily in nociceptive pulpal axons in the peripheral pulp that co-express calci-

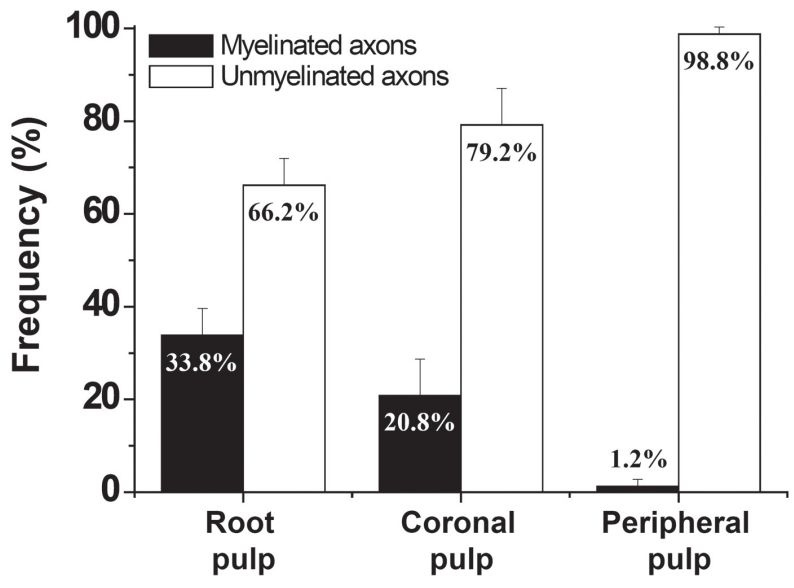

Fig. 3 Frequency (mean \pm S.D., \%) of PV-immunopositive myelinated and unmyelinated axons in the root (radicular) pulp, the core of the coronal pulp, and the peripheral pulp of human upper premolars. Data are modified from the study by Kim et al. [3].

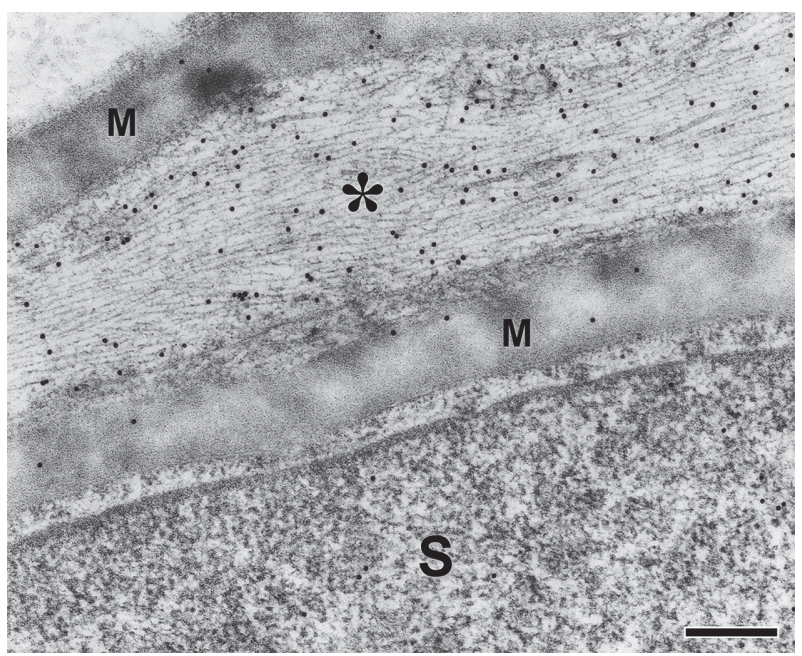

Fig. 4 Electron micrograph showing immunogold labeling for glutamate in a myelinated axon (asterisk) in the rat upper molar pulp. Note the high density of gold particles coding for glutamate within the axoplasm, suggesting a signaling, rather than metabolic, role for glutamate. $\mathrm{M}$ indicates myelin sheath. $\mathrm{S}$ indicates a Schwann cell nucleus. Scale bar $=500 \mathrm{~nm}$

tonin gene-related peptide (CGRP) [26]. Conversely, in the TG, $\mathrm{HCN}$ is co-expressed with neurofilament 200 (NF200)- or PV-positive, large-sized mechanosensitive neurons, but rarely expressed in small-sized, CGRPand isolectin B4 (IB4)-positive neurons. They are densely expressed as ring-like structures at the peripheral plasma membrane of the neuronal cell body rather than at the cytoplasm in the TG. The numbers of HCN1+ and $\mathrm{HCN} 2+$ neuronal cell bodies in the TG significantly increased throughout the maxillary region of the TG following pulpal inflammation of the maxillary teeth, which are innervated by a small number of neurons. These findings suggested that $\mathrm{HCN}$-mediated inflammatory pain may be controlled by two distinct neuronal types in two distinct sites, that is, the cell bodies of mechanosensitive neurons in the TG and the nociceptive axons in the dental pulp. These findings are also consistent with the existence of intercellular communication, perhaps through a diffusible molecule or molecules, under conditions of pulpal inflammation, between the mechanosensitive neurons innervating the dental pulp and other non-inflamed tissues $[27,28]$.

\section{Peripheral glutamate signaling in nociception}

Peripheral release of glutamate and the expression of glutamate receptors are upregulated following inflammation

The transmitter glutamate is produced by deamination of glutamine in the cell bodies of neurons in the dorsal root ganglia (DRG) and TG. It is then transported to the peripheral axons, as evidenced by the existence of glutamate in pulpal axons at a concentration much higher than what would be expected by its metabolic function, and by the accumulation of 
glutamate in the sensory root proximal to the site of a crush injury (Fig. 4) [29-31]. Glutamate release from peripheral axons and dental pulp can be triggered by electrical, chemical, and thermal stimuli [32,33]. Receptors for transmitter glutamate (GluR), including a variety of ionotropic $\alpha$-amino-3-hydroxy-5-methyl-4-isoxazolepropionic acid (AMPA), kainate, and $N$-methyl-D-aspartate (NMDA), and metabotropic glutamate receptors, are also expressed in peripheral myelinated and unmyelinated axons [34-36]. In addition, their expression is increased following tissue injury and inflammation [31,37-41]. Many reports in the literature have supported the hypothesis that glutamate is released from peripheral axons, which mediates nociception via binding to GluR on the axons themselves (autocrine activation) and/or on adjacent axons (paracrine activation) [30].

\section{Peripheral glutamate signaling mediates normal and pathologic} nociception

Several lines of evidence have suggested that peripheral glutamate signaling plays an important role in the transmission of nociception under normal and pathological conditions; thus, 1) application of L-glutamate to the rat skin excites $\mathrm{A} \delta$ and $\mathrm{C}$ fibers, but not $\mathrm{A} \beta$ fibers, and induces their sensitization to heat (thermal hyperalgesia) [42]; 2) injecting glutamate into the human masseter muscle or temporomandibular joint causes acute pain and/ or mechanical allodynia [43-47]; and 3) intraplantar injections of AMPA, kainate, or NMDA receptor agonists cause thermal and mechanical hyperalgesia and mechanical allodynia, which are blocked by the corresponding antagonists [48-50].

Expression of vesicular glutamate transporter 1 (VGLUT1) and VGLUT2 in primary sensory neurons

Vesicular glutamate transporters (VGLUTs), which are integral proteins in the membrane of synaptic vesicles, are involved in the loading of glutamate into synaptic vesicles and its release, and they are widely used as markers for neurons that use glutamate as a neurotransmitter [51,52]. VGLUT1 and VGLUT2, two major isoforms of VGLUT, show neural circuit-specific and complementary expression patterns in the central nervous system, and they are expressed in distinct subsets of primary sensory neurons [52,53]. Thus, VGLUT1 is expressed in neurons that also express markers for lowthreshold mechanoreceptive neurons NF200 or PV, and primarily project to laminae III/IV of the spinal dorsal horn. VGLUT2 is expressed in neurons that also express markers for nociceptive neurons substance P (SP), CGRP, and TRPV1, and they primarily project to laminae I/II of the spinal dorsal horn [54-58]. In addition, studies analyzing the effect of experimental deletion of the mouse genes encoding for VGLUT (global and conditional heterozygous VGLUT ${ }^{+/}$mice since homozygous VGLUT1 1 - or VGLUT2 ${ }^{-/}$ mice are not viable) $[59,60]$ have indicated involvement of VGLUT2 in acute and pathologic pain, but no clear evidence for a role for VGLUT1 in nociception (i.e. heterozygous VGLUT1 ${ }^{+/}$mice showed no change in the response to painful stimuli under normal and pathological conditions) $[58,61]$. Therefore, accumulating evidence points to the involvement of VGLUT1 primarily in the transmission of mechano-sensation and proprioception and the involvement of VGLUT2 primarily in the transmission of nociception.

\section{Glutamate signaling in dental pulp}

\section{Pulpal axons express VGLUT1 and VGLUT2}

It has been shown that VGLUT1 and VGLUT2 are expressed in many pulpal axons, suggesting that VGLUT1- as well as VGLUT2-mediated glutamate signaling is involved in pulpal nociception [4]. Since VGLUT1 is primarily expressed in mechanosensitive neurons (see above) and dental pulp is primarily involved in nociception, it is assumed that VGLUT1 is expressed in a specific subset of sensory afferents $(A \beta$ low-threshold mechanosensitive) in dental pulp that are involved in nociception. This is supported by observations that about $20 \%$ of the axons innervating dental pulp are $A \beta$ large myelinated fibers [2] and about $20 \%$ of the $A \beta$ large myelinated fibers are involved in nociception $[14,15]$. If this is correct, then the neural circuitry for nociception and the mechanism for processing pain information in the dental pulp may be different from those in other tissues.

VGLUT and soluble NSF attachment protein receptor (SNARE), which are two classes of proteins associated with synaptic vesicle exocytosis, are densely expressed in the varicosities of pulpal axons, suggesting that glutamate may be released from the pulpal axons at those varicosities (similar to the terminals of the central axons in the spinal cord, which are the sites for transmitter glutamate release) [4,6,7,62-64]. Reportedly, many axons possessing varicosities expressed VGLUT in the peripheral pulp and many of those axons entered the dentinal tubules [4]. Taken together with another observation that metabotropic glutamate receptor 5 (mGluR5) is also expressed in axons in the peripheral pulp [63], it suggests that the primary site of glutamate signaling associated with dental nociception is the peripheral pulp.

\section{VGLUT2 in the pulpal axons is upregulated following inflammation}

VGLUT2 (but not VGLUT1) is upregulated in TG neurons and peripheral pulp axons following experimental pulpal inflammation (using complete Freund's adjuvant (CFA)) [6]. mGluR5 is upregulated in pulpal axons following dentin injury [63]. These findings suggest that, following inflammation, the VGLUT2-mediated glutamate release from pulpal axons increases, leading to the activation and subsequent heterologous or autologous upregulation of GluRs in pulpal nociceptive axons (A $\delta$ and $\mathrm{C}$ fibers, but not $A \beta$ fibers), which in turn can contribute to their sensitization and eventually to the development of pathologic pain [42]. The release of glutamate may also evoke the release of neuropeptides (among them, CGRP) from pulpal axons, which is known to induce neurogenic inflammation that can further contribute to sensitization of the pulpal nociceptive axons [65].

The expression of VGLUT1 in pulpal axons and TG neurons remains virtually unchanged following pulpal inflammation, suggesting that the VGLUT1-mediated glutamate signaling by pulpal axons may be involved in the mechanisms of acute nociceptive pain but not in the mechanisms of inflammatory pain [6]. The enhanced glutamate release from rat pulpal axons following inflammation follows the pattern of increases in glutamate release from peripheral axons following inflammation or tissue injury elsewhere in the body [30]. VGLUT1 and VGLUT2 are also expressed in CD64+ inflammatory cells that infiltrate pulp following inflammation [6], suggesting that non-neuronal cells may also be related to the increase in VGLUT-mediated glutamate signaling following inflammation of the pulp.

\section{Expression of VGLUT in the TG neurons and pulpal axons that express} TRPM8

Sensory neurons that innervate pulp express a variety of receptors and ion channels, the activation of which can evoke glutamate release from their central and/or peripheral axons. For example, it was shown that activation of TRPM8 in neurons induces release of glutamate from their central afferents, which plays a crucial role in the transmission of TRPM8-mediated signaling of cold $[66,67]$. In addition, many TRPM8-expressing TG neurons and pulpal axons express VGLUT2 (but not VGLUT1) [7]. Considering that both VGLUT2 and TRPM8 in the primary sensory neurons have been implicated in the mediation of acute nociceptive and pathologic pain $[68,69]$, it seems likely that VGLUT2-mediated glutamate signaling is involved in the transmission of TRPM8-mediated noxious cold. Furthermore, the expression of VGLUT2 in TG neurons is upregulated following pulpal inflammation, whereas the expression of TRPM8 is not significantly changed [7]. Since both TRPM8 and VGLUT2 are implicated in cold hypersensitivity following inflammation [69-71], it is reasonable to assume that cold hypersensitivity following pulpal inflammation is induced by upregulation of the expression of VGLUT2 in the TRPM8-expressing TG neurons, rather than by the direct effect of TRPM8 upregulation. The activation of TRPM8 following pulpal inflammation may further enhance the increase in VGLUT2-mediated glutamate release through an indirect mechanism. Several studies also reported no change in the expression of TRPM8 in DRG neurons following nerve injury and inflammation [72,73]. One study reported the downregulation of TPRM 8 in the radicular pulp of the human teeth with irreversible pulpitis [74]. The discrepancy may be due to differences in rats versus humans or in pulp versus TG or DRG.

\section{Glutamate release from odontoblasts}

That odontoblasts can also engage in glutamate signaling is supported by the following observations: 1) odontoblasts contain levels of glutamate that are far too high to be explained by their metabolic needs, 2) the levels of glutamate in the odontoblasts (and the expression of the mGluR5 receptor in pulpal axons that are adjacent to them) are increased following pulpal inflammation, and 3) glutamate release from odontoblasts is increased by 
experimentally raising the intracellular $\mathrm{Ca}^{2+}$ [31]. Additionally, mechanical stimulation of the odontoblasts in a coculture of odontoblasts and TG neurons was shown to induce $\mathrm{Ca}^{2+}$ influx in adjacent odontoblasts and TG neurons, which is inhibited by the application of mGluR antagonists [75]. These findings provided morphological and electrophysiological evidence supporting the notion that odontoblasts, when activated, release glutamate, which then activates GluR expressed on adjacent pulpal nociceptive axons, thus playing a role in the mechanisms of acute dental pain and hypersensitivity following inflammation.

\section{Acknowledgments}

The authors are very grateful to Prof. Koichi Iwata for encouraging and promoting this research and for his great contribution to the development of orofacial neuroscience. The authors also thank Dr. Juli Valtschanoff for careful reading of the manuscript. This work was supported by the National Research Foundation of Korea (NRF) grant funded by the Korea government (MSIT, NRF-2017R1A5A2015391, NRF-2017R1A2B2003561).

\section{Conflict of interest}

The authors declare that they have no conflict of interest.

\section{References}

1. Hildebrand C, Fried K, Tuisku F, Johansson CS (1995) Teeth and tooth nerves. Prog Neurobiol 45, 165-222.

2. Paik SK, Park KP, Lee SK, Ma SK, Cho YS, Kim YK et al. (2009) Light and electron microscopic analysis of the somata and parent axons innervating the rat upper molar and lower incisor pulp. Neuroscience 162, 1279-1286.

3. Kim TH, Park SK, Choi SY, Lee JS, Bae YC (2017) Morphologic change of parvalbuminpositive myelinated axons in the human dental pulp. J Endod 43, 977-981.

4. Paik SK, Kim SK, Choi SJ, Yang ES, Ahn SH, Bae YC (2012) Vesicular glutamate transporters in axons that innervate the human dental pulp. J Endod 38, 470-474.

5. Lee K, Lee BM, Park CK, Kim YH, Chung G (2019) Ion channels involved in tooth pain. Int J Mol Sci 20, 2266.

6. Yang ES, Jin MU, Hong, JH, Kim YS, Choi SY, Kim TH et al. (2014) Expression of vesicular glutamate transporters VGLUT1 and VGLUT2 in the rat dental pulp and trigeminal ganglion following inflammation. PloS One 9, e109723.

7. Kim YS, Kim TH, McKemy DD, Bae YC (2015) Expression of vesicular glutamate transporters in transient receptor potential melastatin 8 (TRPM8)-positive dental afferents in the mouse. Neuroscience 303, 378-388.

8. Byers MR, Suzuki H, Maeda T (2003) Dental neuroplasticity, neuro-pulpal interactions, and nerve regeneration. Microsc Res Tech 60, 503-515.

9. Lisney SJ (1978) Some anatomical and electrophysiological properties of tooth-pulp afferents in the cat. J Physiol 284, 19-36.

10. Cadden SW, Lisney SJ, Matthews B (1983) Thresholds to electrical stimulation of nerves in cat canine tooth-pulp with A beta-, A delta- and C-fibre conduction velocities. Brain Res 261, 31-41.

11. Fried K, Arvidsson J, Robertson B, Brodin E, Theodorsson E (1989) Combined retrograde tracing and enzyme/immunohistochemistry of trigeminal ganglion cell bodies innervating tooth pulps in the rat. Neuroscience 33, 101-109.

12. Johansson CS, Hildebrand C, Povlsen B (1992) Anatomy and developmental chronology of the rat inferior alveolar nerve. Anat Rec 234, 144-152.

13. Sugimoto T, Takemura M, Wakisaka S (1988) Cell size analysis of primary neurons innervating the cornea and tooth pulp of the rat. Pain 32, 375-381.

14. Fried K, Sessle BJ, Devor M (2011) The paradox of pain from tooth pulp: low-threshold "algoneurons"? Pain 152, 2685-2689.

15. Djouhri L, Lawson SN (2004) Abeta-fiber nociceptive primary afferent neurons: a review of incidence and properties in relation to other afferent A-fiber neurons in mammals. Brain Res Rev 46, 131-145.

16. Light AR, Perl ER (1979) Spinal termination of functionally identified primary afferent neurons with slowly conducting myelinated fibers. J Comp Neurol 186, 133-150.

17. Nicol MJ, Walmsley B (1991) A serial section electron microscope study of an identified Ia afferent collateral in the cat spinal cord. J Comp Neurol 314, 257-277.

18. Peng YB, Ringkamp M, Campbell JN, Meyer RA (1999) Electrophysiological assessment of the cutaneous arborization of Adelta-fiber nociceptors. J Neurophysiol 82, 1164-1177.

19. Holland GR, Robinson PP (1983) The number and size of axons at the apex of the cat's canine tooth. Anat Rec 205, 215-222.

20. Naftel JP, Bernanke JM, Qian XB (1994) Quantitative study of the apical nerve fibers of adult and juvenile rat molars. Anat Rec 238, 507-516.

21. Bae JY, Mun CJ, Kim YS, Ahn DK, Bae YC (2018) Quantitative ultrastructural analysis of fibers expressing parvalbumin, calretinin, calbindin D-28k, stage specific embryonic antigen- 4 , and phosphorylated neurofilament 200 in the peripheral sensory root of the rat trigeminal ganglion. J Comp Neurol 526, 2204-2214.

22. Kim YS, Jung HK, Kwon TK, Kim CS, Cho JH, Ahn DK et al. (2012) Expression of transient receptor potential ankyrin 1 in human dental pulp. J Endod 38, 1087-1092.

23. Momin A, Cadiou H, Mason A, McNaughton PA (2008) Role of the hyperpolarizationactivated current Ih in somatosensory neurons. J Physiol 586, 5911-5929.

24. Emery EC, Young GT, Berrocoso EM, Chen L, McNaughton PA (2011) HCN2 ion channels play a central role in inflammatory and neuropathic pain. Science 333, 1462-1466.

25. Emery EC, Young GT, McNaughton PA (2012) HCN2 ion channels: an emerging role as the pacemakers of pain. Trends Pharmacol Sci 33, 456-463.

26. Cho YS, Kim YS, Moozhayil SJ, Yang ES, Bae YC (2015) The expression of hyperpolarization-activated cyclic nucleotide-gated channel 1 (HCN1) and $\mathrm{HCN} 2$ in the rat trigeminal ganglion, sensory root, and dental pulp. Neuroscience 291, 15-25.
27. Takeda M, Tanimoto T, Nasu M, Ikeda M, Kadoi J, Matsumoto S (2005) Activation of NK1 receptor of trigeminal root ganglion via substance $P$ paracrine mechanism contributes to the mechanical allodynia in the temporomandibular joint inflammation in rats. Pain 116, 375-385.

28. Shinoda M, Asano M, Omagari D, Honda K, Hitomi S, Katagiri A et al. (2011) Nerve growth factor contribution via transient receptor potential vanilloid 1 to ectopic orofacial pain. J Neurosci 31, 7145-7155.

29. Keast JR, Stephensen TM (2000) Glutamate and aspartate immunoreactivity in dorsal root ganglion cells supplying visceral and somatic targets and evidence for peripheral axonal transport. J Comp Neurol 424, 577-587.

30. Miller KE, Hoffman EM, Sutharshan M, Schechter R (2011) Glutamate pharmacology and metabolism in peripheral primary afferents: physiological and pathophysiological mechanisms. Pharmacol Ther 130, 283-309.

31. Cho YS, Ryu CH, Won JH, Vang H, Oh SB, Ro JY et al. (2016) Rat odontoblasts may use glutamate to signal dentin injury. Neuroscience 335, 54-63.

32. deGroot J, Zhou S, Carlton SM (2000) Peripheral glutamate release in the hindpaw following low and high intensity sciatic stimulation. Neuroreport 11, 497-502.

33. Jin YH, Nishioka H, Wakabayashi K, Fujita T, Yonehara N (2006) Effect of morphine on the release of excitatory amino acids in the rat hind instep: Pain is modulated by the interaction between the peripheral opioid and glutamate systems. Neuroscience 138, 1329-1339.

34. Coggeshall RE, Carlton SM (1998) Ultrastructural analysis of NMDA, AMPA, and kainate receptors on unmyelinated and myelinated axons in the periphery. J Comp Neurol 391, $78-86$.

35. Bhave G, Karim F, Carlton SM, Gereau RW 4th (2001) Peripheral group I metabotropic glutamate receptors modulate nociception in mice. Nat Neurosci 4, 417-423.

36. Carlton SM (2001) Peripheral excitatory amino acids. Curr Opin Pharmacol 1, 52-56.

37. Westlund KN, Sun YC, Sluka KA, Dougherty PM, Sorkin LS, Willis WD (1992) Neural changes in acute arthritis in monkeys. II. Increased glutamate immunoreactivity in the medial articular nerve. Brain Res Rev 17, 15-27.

38. Omote K, Kawamata T, Kawamata M, Namiki A (1998) Formalin-induced release of excitatory amino acids in the skin of the rat hindpaw. Brain Res 787, 161-164.

39. Carlton SM, Coggeshall RE (1999) Inflammation-induced changes in peripheral glutamate receptor populations. Brain Res 820, 63-70.

40. Lawand NB, McNearney T, Westlund KN (2000) Amino acid release into the knee joint: key role in nociception and inflammation. Pain $86,69-74$

41. Du J, Zhou S, Carlton SM (2006) Kainate-induced excitation and sensitization of nociceptors in normal and inflamed rat glabrous skin. Neuroscience 137, 999-1013.

42. Du J, Koltzenburg M, Carlton SM (2001) Glutamate-induced excitation and sensitization of nociceptors in rat glabrous skin. Pain 89, 187-198.

43. Cairns BE, Hu JW, Arendt-Nielsen L, Sessle BJ, Svensson P (2001) Sex-related differences in human pain and rat afferent discharge evoked by injection of glutamate into the masseter muscle. J Neurophysiol 86, 782-791.

44. Cairns BE, Svensson P, Wang K, Hupfeld S, Graven-Nielsen T, Sessle BJ et al. (2003) Activation of peripheral NMDA receptors contributes to human pain and rat afferent discharges evoked by injection of glutamate into the masseter muscle. J Neurophysiol 90, 2098-2105.

45. Svensson P, Cairns BE, Wang K, Hu JW, Graven-Nielsen T, Arendt-Nielsen L et al. (2003) Glutamate-evoked pain and mechanical allodynia in the human masseter muscle. Pain 101, 221-227.

46. Svensson P, Wang K, Arendt-Nielsen L, Cairns BE, Sessle BJ (2005) Pain effects of glutamate injections into human jaw or neck muscles. J Orofac Pain 19, 109-118

47. Alstergren P, Ernberg M, Nilsson M, Hajati AK, Sessle BJ, Kopp S (2010) Glutamateinduced temporomandibular joint pain in healthy individuals is partially mediated by peripheral NMDA receptors. J Orofac Pain 24, 172-180.

48. Jackson DL, Graff CB, Richardson JD, Hargreaves KM (1995) Glutamate participates in the peripheral modulation of thermal hyperalgesia in rats. Eur J Pharmacol 284, 321-325.

49. Carlton SM, Hargett GL, Coggeshall RE (1995) Localization and activation of glutamate receptors in unmyelinated axons of rat glabrous skin. Neurosci Lett 197, 25-28.

50. Zhou S, Bonasera L, Carlton SM (1996) Peripheral administration of NMDA, AMPA or KA results in pain behaviors in rats. Neuroreport 7, 895-900.

51. Varoqui H, Schafer MK, Zhu H, Weihe E, Erickson JD (2002) Identification of the differentiation-associated $\mathrm{Na}^{+} / \mathrm{PI}$ transporter as a novel vesicular glutamate transporter expressed in a distinct set of glutamatergic synapses. J Neurosci 22, 142-155.

52. Fremeau RT Jr, Voglmaier S, Seal RP, Edwards RH (2004) VGLUTs define subsets of excitatory neurons and suggest novel roles for glutamate. Trends Neurosci 27, 98-103.

53. Kaneko T, Fujiyama F (2002) Complementary distribution of vesicular glutamate transporters in the central nervous system. Neurosci Res 42, 243-250.

54. Todd AJ, Hughes DI, Polgar E, Nagy GG, Mackie M, Ottersen OP et al. (2003) The expression of vesicular glutamate transporters VGLUT1 and VGLUT2 in neurochemically defined axonal populations in the rat spinal cord with emphasis on the dorsal horn. Eur J Neurosci 17, 13-27.

55. Alvarez FJ, Villalba RM, Zerda R, Schneider SP (2004) Vesicular glutamate transporters in the spinal cord, with special reference to sensory primary afferent synapses. J Comp Neurol 472, 257-280

56. Landry M, Bouali-Benazzouz R, El Mestikawy S, Ravassard P, Nagy F (2004) Expression of vesicular glutamate transporters in rat lumbar spinal cord, with a note on dorsal root ganglia. J Comp Neurol 468, 380-394.

57. Brumovsky P, Watanabe M, Hokfelt T (2007) Expression of the vesicular glutamate transporters- 1 and -2 in adult mouse dorsal root ganglia and spinal cord and their regulation by nerve injury. Neuroscience 147, 469-490.

58. Malet M, Brumovsky PR (2015) VGLUTs and glutamate synthesis-focus on DRG neurons and pain. Biomolecules 5, 3416-3437.

59. Wojcik SM, Rhee JS, Herzog E, Sigler A, Jahn R, Takamori S et al. (2004) An essential role for vesicular glutamate transporter 1 (VGLUT1) in postnatal development and control of quantal size. Proc Natl Acad Sci U S A 101, 7158-7163.

60. Wallén-Mackenzie A, Gezelius H, Thoby-Brisson M, Nygård A, Enjin A, Fujiyama F et al (2006) Vesicular glutamate transporter 2 is required for central respiratory rhythm generation but not for locomotor central pattern generation. J Neurosci 26, 12294-12307.

61. Leo S, Moechars D, Callaerts-Vegh Z, D’Hooge R, Meert T (2009) Impairment of VGLUT2 but not VGLUT1 signaling reduces neuropathy-induced hypersensitivity. Eur J Pain 13, 1008-1017.

62. Norlin T, Hilliges M, Brodin L (1999) Immunohistochemical demonstration of exocytosis- 
regulating proteins within rat molar dentinal tubules. Arch Oral Biol 44, 223-231.

63. Kim YS, Kim YJ, Paik SK, Cho YS, Kwon TG, Ahn DK et al. (2009) Expression o metabotropic glutamate receptor mGluR5 in human dental pulp. J Endod 35, 690-694

64. Honma S, Taki K, Lei S, Niwa H, Wakisaka S (2010) Immunohistochemical localization of SNARE proteins in dental pulp and periodontal ligament of the rat incisor. Anat Rec (Hoboken) 293, 1070-1080

65. Jackson DL, Hargreaves KM (1999) Activation of excitatory amino acid receptors in bovine dental pulp evokes the release of iCGRP. J Dent Res 78, 54-60.

66. Baccei ML, Bardoni R, Fitzgerald M (2003) Development of nociceptive synaptic inputs to the neonatal rat dorsal horn: glutamate release by capsaicin and menthol. J Physiol 549, 231-242

67. Wrigley PJ, Jeong HJ, Vaughan CW (2009) Primary afferents with TRPM8 and TRPA1 profiles target distinct subpopulations of rat superficial dorsal horn neurones. Br J Pharmacol 157, 371-380.

68. McKemy DD, Neuhausser WM, Julius D (2002) Identification of a cold receptor reveals a general role for TRP channels in thermosensation. Nature 416, 52-58.

69. Rogoz K, Lagerstrom MC, Dufour S, Kullander K (2012) VGLUT2-dependent glutamatergic transmission in primary afferents is required for intact nociception in both acute and persistent pain modalities. Pain 153, 1525-1536.

70. Colburn RW, Lubin ML, Stone DJ Jr., Wang Y, Lawrence D, D'Andrea MR et al. (2007) Attenuated cold sensitivity in TRPM8 null mice. Neuron 54, 379-386.

71. Knowlton WM, Palkar R, Lippoldt EK, McCoy DD, Baluch F, Chen J et al. (2013) A sensory-labeled line for cold: TRPM8-expressing sensory neurons define the cellular basis for cold, cold pain, and cooling-mediated analgesia. J Neurosci 33, 2837-2848.

72. Obata K, Katsura H, Mizushima T, Yamanaka H, Kobayashi K, Dai Y et al. (2005) TRPA1 induced in sensory neurons contributes to cold hyperalgesia after inflammation and nerve injury. J Clin Invest 115, 2393-2401.

73. Dhaka A, Earley TJ, Watson J, Patapoutian A (2008) Visualizing cold spots: TRPM8expressing sensory neurons and their projections. J Neurosci 28, 566-575.

74. Alvarado LT, Perry GM Alvarado LT, Perry GM, Hargreaves KM, Henry MA (2007) TRPM8 Axonal expression is decreased in painful human teeth with irreversible pulpitis and cold hyperalgesia. J Endod 33, 1167-1171.

75. Nishiyama A, Sato M, Kimura M, Katakura A, Tazaki M, Shibukawa Y (2016) Intercellular signal communication among odontoblasts and trigeminal ganglion neurons via glutamate. Cell Calcium 60, 341-355. 